\title{
ANÁLISE DA QUALIDADE DA ÁGUA PARA O CONSUMO HUMANO DO ASSENTAMENTO JERUSALÉM NO MUNICÍPIO DE RUBIM-MG
}

\section{ARTIGO ORIGINAL}

TEIXEIRA, Hiago dos Santos ${ }^{1}$, SOUZA, Davi Ramalho 2, GAMA, Ednilton Moreira ${ }^{3}$, MATOS, Roberta Pereira ${ }^{4}$

TEIXEIRA, Hiago dos Santos. Et al. Análise da qualidade da água para o consumo humano do assentamento Jerusalém no município de Rubim-MG. Revista Científica Multidisciplinar Núcleo do Conhecimento. Ano. 07, Ed. 02, Vol. 01, pp. 119130. Fevereiro de 2022. ISSN: 2448-0959, Link de acesso: https://www.nucleodoconhecimento.com.br/engenharia-agricola/qualidadeda-agua

\section{RESUMO}

A água é um dos mais importantes recursos do ecossistema sendo utilizada em atividades do dia a dia e para o consumo humano. A água utilizada no consumo humano não deve conter a presença de organismos patogênicos e substâncias nocivas para a saúde. Considerando que nas áreas rurais o acesso à água potável é negligenciado, quando comparado com as áreas urbanas, este trabalho tem como objetivo avaliar a qualidade da água utilizada pelos moradores do Assentamento

${ }^{1}$ Graduação em Engenharia Agronômica. ORCID: 0000-0001-8266-2304

2 Graduação em Engenharia Ambiental, Graduando em Engenharia Agronômica. ORCID: 0000-0003-0316-0213

3 Doutor em Ciências - Química Analítica, Mestre em Química Analítica, Especialização em Ensino de Química, Licenciatura em Química. ORCID: 0000-00024336-9233

${ }^{4}$ Orientador. ORCID: 0000-0003-0481-9710

RC: 106324

Disponível em: https://www.nucleodoconhecimento.com.br/engenharia-agricola/qualidade-daagua 
Jerusalém no Município de Rubim - MG utilizando um Kit Técnico de Potabilidade (Alfakit). Foram coletadas 12 amostras de água em diferentes casas do assentamento, sendo 3 (três) de poço artesiano (PA), 3 (três) de caminhão pipa (CP), 3 (três) de chuva tratadas com solução de hipoclorito de sódio 2,5\% (CH) e 3 (três) de chuva sem solução de hipoclorito de sódio 2,5\% (CSH). Foram realizadas análises físicoquímicas ( $\mathrm{pH}$, cloro, cloretos, dureza total, ferro, cor, turbidez) e microbiológicas (Coliformes totais e E. coli) utilizando um Kit Técnico de Potabilidade (Alfakit), onde as análises são realizadas por comparação em cartela colorimétrica e métodos titulométricos. Os resultados foram comparados com os valores de referência estabelecidos pela Portaria $n^{\circ}$ 5/2017 do Ministério da Saúde e demonstraram que, em relação aos parâmetros físico-químicos analisados, a turbidez e cor estão fora do Valor Máximo Permitido. Esses dois parâmetros estão interligados e apresentam mais conotação estética do que sanitária, podendo ser corrigidos com a limpeza dos reservatórios e filtragem da água para o consumo. Já no que se refere à análise microbiológica, não houve presença de coliformes totais. Foi identificada a presença de E. coli apenas nas amostras advindas de caminhão pipa fornecida pela COPASA. Por fim, uma atenção deve ser dada em relação à água proveniente do poço artesiano (PA-1), pois este apresentou coliformes termotolerantes ( $E$. coll), o que indica a presença direta de fezes na água consumida e a torna inapropriada para o consumo humano.

Palavras-Chave: População rural, Água potável, Alfakit.

\section{INTRODUÇÃO}

A água é um dos mais importantes recursos do ecossistema, sendo utilizada, principalmente, em atividades econômicas como a agropecuária e indústria, além de aplicações cotidianas como higiene e alimentação (PATIAS et al., 2016). De acordo com Zerwes et al. (2015), o corpo humano apresenta em sua composição $75 \%$ de água, já nos vegetais esse valor chega a $90 \%$ e, a sua falta, pode ocasionar a deterioração de ecossistemas.

RC: 106324

Disponível em: https://www.nucleodoconhecimento.com.br/engenharia-agricola/qualidade-daagua 
De acordo com Birkheuer et al. (2017), por ser a substância de maior valor biológico, a água serve de veículo para vários agentes potencialmente patogênicos que alteram sua função nutricional, como alguns microrganismos patogênicos a exemplo as bactérias do grupo coliformes. Diante disso, a população deve estar atenta aos fatores que alteram negativamente a qualidade da água que consomem. Segundo Oliveira (2018), a água utilizada para consumo doméstico deve apresentar características sanitárias e toxicológicas adequadas sem a presença de microrganismos patogênicos e substâncias nocivas à saúde a fim de garantir o bem-estar da população.

De acordo com Cabral e Araújo (2016), a população mundial está dividida entre habitantes rurais e urbanos e, a maioria dos habitantes que não tem acesso à água e ao saneamento básico, são moradores de áreas rurais. Cerca de $75 \%$ dessa população, em torno de oito a cada dez habitantes de zonas rurais, não possuem acesso a fontes de água potável. No meio rural, o risco de ocorrência de surtos de doenças de veiculação hídrica é mais alto que nas zonas urbanas de acordo com Brito (2013). Isso ocorre, principalmente, devido a possibilidade de contaminação bacteriana de águas, que muitas vezes são captadas em poços velhos, vedados de forma errônea e que estão instalados próximos de fontes de contaminação, como fossas e áreas de pastagem ocupadas por animais.

Segundo Brito (2013), o padrão de potabilidade é definido como as quantidades limites que podem ser toleradas na água de abastecimento com relação aos diversos elementos. Para atender a esse padrão de potabilidade as amostras devem atender à legislação vigente do Ministério da Saúde, visando garantir o padrão de potabilidade e os procedimentos de controle de vigilância da qualidade da água para consumo humano. Este monitoramento é realizado por intermédio de análises laboratoriais que avaliam os principais parâmetros de qualidade de água, que consistem em avaliações físico-químicos (cor, turbidez, condutividade elétrica, temperatura, $\mathrm{pH}$, alcalinidade, dureza total, ferro, cloretos, oxigênio dissolvido, oxigênio consumido, cloro residual

RC: 106324

Disponível em: https://www.nucleodoconhecimento.com.br/engenharia-agricola/qualidade-daagua 
livre, sólidos totais, amônia) e microbiológicos (coliformes totais e termotolerantes e bactérias mesófilas aeróbias).

Tendo em vista que nas áreas rurais o acesso à água potável é negligenciado, quando comparado com as áreas urbanas, esse trabalho tem como objetivo avaliar a potabilidade da água utilizada pelos moradores do Assentamento Jerusalém, localizado no município de Rubim - MG, utilizando um Kit Técnico de Potabilidade (Alfakit).

\section{MATERIAL E MÉTODOS}

\section{COLETA DAS AMOSTRAS}

O presente estudo foi realizado no Assentamento Jerusalém formado por 60 famílias assentadas, localizado a $7 \mathrm{~km}$ da cidade de Rubim - MG, na zona rural do município (Figura 1).

Inicialmente, foi perguntado aos moradores sobre a forma de captação e armazenamento da água e se eles tinham conhecimento acerca das doenças que podem ser transmitidas pela água.

RC: 106324

Disponível em: https://www.nucleodoconhecimento.com.br/engenharia-agricola/qualidade-daagua 
Figura 1: Localização do Assentamento Jerusalém.

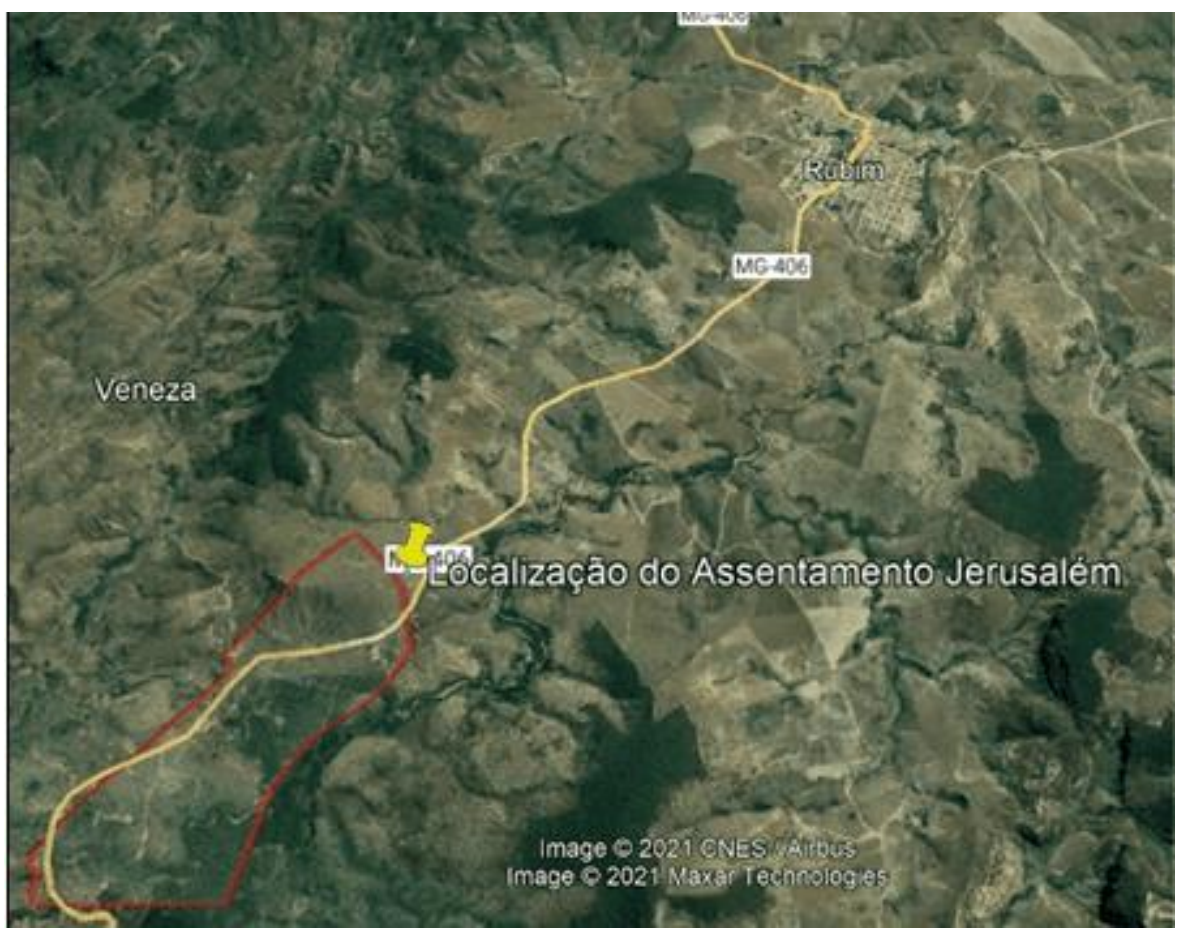

Fonte: Google Earth 2021.

As principais formas de captação e armazenamento de água no Assentamento são: poço artesiano, cisterna e caminhão pipa (Figura 2). Com as informações obtidas, foi programado a realização da coleta de amostras para análise físico-química e biológica.

RC: 106324

Disponível em: https://www.nucleodoconhecimento.com.br/engenharia-agricola/qualidade-daagua 
Figura 2: (A) Armazenamento de água de poço (B) Armazenamento de água em cisterna utilizada pelos moradores do Assentamento Jerusalém no município de Rubim-MG.

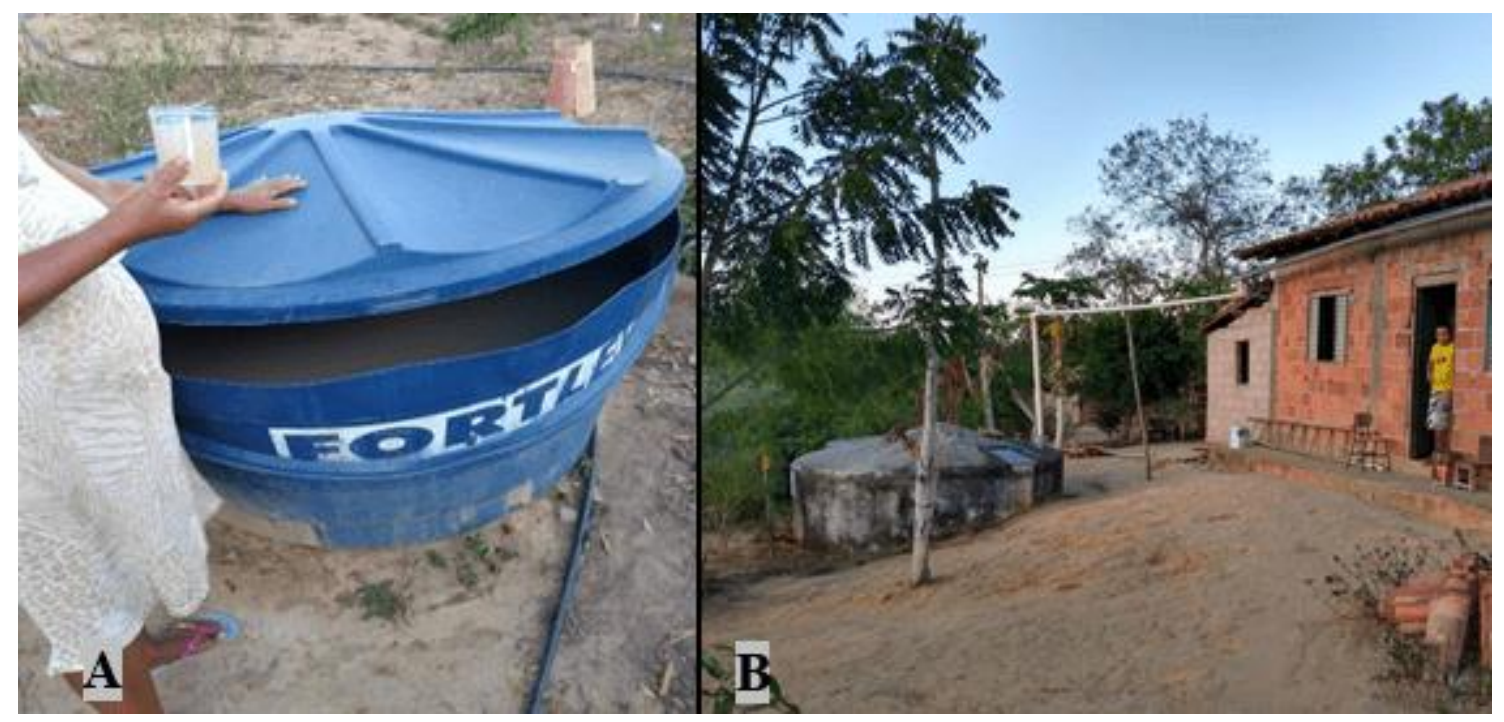

Fonte: Autores (2019)

As coletas de amostras de água no Assentamento Jerusalém foram realizadas no dia 15 de dezembro de 2019. Para a coleta, foram utilizados frascos de polietileno previamente esterilizados e, no momento de cada uma das coletas, foi realizada uma esterilização prévia das saídas de água. Posteriormente, a torneira foi deixada aberta por um tempo de 5 minutos, para eliminar possíveis contaminantes e impurezas presentes no percurso da água.

Coletou-se 12 amostras de água utilizadas para consumo humano em diferentes casas do assentamento, onde 3 (três) foram de poço artesiano (PA), 3 (três) de caminhão pipa (CP), 3 (três) de chuva tratadas com solução de hipoclorito de sódio $2,5 \%(\mathrm{CH})$ e 3 (três) de chuva sem solução de hipoclorito de sódio 2,5\% (CSH). 


\section{MÉTODO DE ANÁLISE DOS PARÂMETROS}

As análises físico-químicas e microbiológicas da água foram realizadas no laboratório do Instituto Federal de Educação Ciência e Tecnologia do Norte de Minas Gerais (IFNMG)- campus Almenara, utilizando um Kit Técnico de Potabilidade (Alfakit) desenvolvido para controle de qualidade da água para consumo humano, onde as análises são realizadas por comparação em cartela colorimétrica e por titulações volumétricas (ALFAKIT, 2019).

Com esse Kit foi possível realizar diversas análises físico-químicas, tais como $\mathrm{pH}$, dureza total, cloretos, cloro residual, ferro, amônia, oxigênio consumido, cor e turbidez e análises microbiológicas (Coliformes totais e Escherichia coli (E.coli).

Para a contabilização dos coliformes totais e E.coli, foi seguida metodologia do Kit técnico de Potabilidade (Alfakit), utilizando uma mini estufa e Colipaper, cujo resultado com manchas azuis detectava presença de E.coli e manchas vermelhas detectava presença de coliformes totais. As análises microbiológicas foram realizadas em apenas uma amostra de cada fonte de consumo, já as análises físico-químicas foram realizadas em duplicata.

\section{COMPARAÇÃO DOS RESULTADOS COM A LEGISLAÇÃO VIGENTE}

Os valores das análises físico-químicas e microbiológicas obtidas foram comparados com os parâmetros estabelecidos pela Portaria ํㅜ 5 de 28 de setembro de 2017 do Ministério da Saúde (BRASIL, 2017) que dispõe sobre o controle e vigilância da qualidade da água para consumo humano.

\section{RESULTADOS E DISCUSSÃO}

Os resultados obtidos das análises físico-químicas estão demonstrados na Tabela 1.

RC: 106324

Disponível em: https://www.nucleodoconhecimento.com.br/engenharia-agricola/qualidade-daagua 
Tabela 1: Parâmetros físico-químicos determinados nas amostras de água do Assentamento Jerusalém, município de Rubim - MG.

\begin{tabular}{|c|c|c|c|c|c|c|c|}
\hline Parâmetros & \multirow[t]{2}{*}{$\mathrm{pH}$} & \multirow{2}{*}{$\begin{array}{l}\text { Cloro } \\
\left(\mathrm{mgL}^{-1}\right. \\
\left.\mathrm{Cl}_{2}\right)\end{array}$} & \multirow{2}{*}{$\begin{array}{l}\text { Cloretos } \\
\left(\mathrm{mgL}^{-1}\right. \\
\left.\mathrm{Cl}^{-}\right)\end{array}$} & \multirow{2}{*}{$\begin{array}{l}\text { Dureza } \\
\text { Total } \\
\left(\mathrm{mgL}^{-1}\right. \\
\left.\mathrm{CaCO}_{3}\right)\end{array}$} & \multirow{2}{*}{$\begin{array}{l}\text { Ferro } \\
\left(\mathrm{mgL}^{-1}\right. \\
\mathrm{Fe})\end{array}$} & \multirow{2}{*}{$\begin{array}{l}\text { Cor } \\
\left(\mathrm{mgL}^{-}\right. \\
\left.{ }^{1} \mathrm{Pt}^{-\mathrm{Co}}\right)\end{array}$} & \multirow{2}{*}{$\begin{array}{l}\text { Turbidez } \\
\text { (NTU) }\end{array}$} \\
\hline Amostras & & & & & & & \\
\hline $\mathrm{CSH} 1$ & 6,9 & 0,1 & 6,25 & 4,1 & 0,25 & 5 & 3 \\
\hline $\mathrm{CSH} 2$ & 7,1 & 0,1 & 2,35 & 4,6 & 0,25 & 3 & 22 \\
\hline $\mathrm{CSH} 3$ & 8,2 & 0,1 & 4,8 & 4,2 & 0,25 & 3 & 27 \\
\hline $\mathrm{CH} 1$ & 6,5 & 0,1 & 0,5 & 1,2 & 0,25 & 5 & 2 \\
\hline $\mathrm{CH} 2$ & 7,6 & 0,1 & 0,4 & 1,4 & 0,25 & 5 & 5 \\
\hline $\mathrm{CH} 3$ & 6,8 & 0,1 & 4,5 & 1,0 & 0,25 & 5 & 7 \\
\hline PA1 & 6,9 & 0,1 & 1,65 & 7,7 & 0,25 & 25 & 30 \\
\hline PA2 & 6,9 & 0,1 & 1,4 & 4,7 & 0,25 & 15 & 9 \\
\hline PA3 & 6,8 & 0,1 & 5,45 & 13,1 & 0,25 & 5 & 25 \\
\hline CP1 & 6,0 & 0,25 & 0,45 & 4,8 & 0,25 & 5 & 18 \\
\hline CP2 & 6,2 & 0,25 & 0,45 & 4,8 & 0,25 & 3 & 6 \\
\hline CP3 & 6,4 & 0,25 & 0,5 & 4,7 & 0,25 & 3 & 15 \\
\hline *VMP & $\begin{array}{l}6,0- \\
9,0\end{array}$ & 2 & 250 & 500 & 0,3 & 15 & 5 \\
\hline
\end{tabular}

*VMP: Valor Máximo Permitido pela legislação - Portaria no 5 de 28 de setembro de 2017 do Ministério da Saúde (BRASIL, 2017). Fonte: Autores (2019)

Todas as amostras apresentaram concentrações de $0,1\left(\mathrm{mgL}^{-1} \mathrm{NH}_{3}\right)$ para amônia e valores de $0,0\left(\mathrm{mgL}^{-1} \mathrm{O}_{2}\right)$ para oxigênio consumido. Os dados demonstram que os parâmetros $\mathrm{pH}$, cloro, cloretos, dureza total, ferro, amônia e oxigênio consumido apresentaram valores dentro dos padrões estabelecidos pela Portaria $n^{\circ} 5$, de 28 de setembro de 2017 do Ministério da Saúde, porém os parâmetros cor e turbidez RC: 106324

Disponível em: https://www.nucleodoconhecimento.com.br/engenharia-agricola/qualidade-daagua 
apresentaram, em alguns pontos de coleta, valores acima do Valor Máximo Permitido (VMP) estabelecido pela legislação.

De acordo com Cabral e Araújo (2016), o pH é uma medida que determina se a água é ácida, básica ou alcalina, que permite acompanhar e melhorar os processos de tratamento e preservação de tubulações contra entupimentos e corrosões. Esse parâmetro não provoca riscos sanitários, mas há uma recomendação de pH para água de consumo humano que varia de 6,0 a 9,0 na água distribuída. Todas as amostras analisadas estavam com valor de $\mathrm{pH}$ dentro do limite estabelecido pela portaria do Ministério da Saúde.

O nitrogênio amoniacal pode ser detectado na água sob duas formas: amônia $\left(\mathrm{NH}_{3}\right)$ e íon amônio $\left(\mathrm{NH}_{4}^{+}\right)$, cuja razão molar é $\mathrm{NH}_{3} / \mathrm{NH}_{4}^{+}$, que depende do $\mathrm{pH}$, da temperatura e da salinidade ou da composição iônica no ambiente aquático. $\mathrm{Em} \mathrm{pH}$ básico predomina a espécie $\mathrm{NH}_{3}$ de maior toxicidade que a $\mathrm{NH}_{4}{ }^{+}$. Segundo Silva et al. (2020), teores elevados de amônia na água podem indicar aumento da carga orgânica proveniente da decomposição de proteínas animais e vegetais, o que pode resultar em aumento do nível de contaminação, como a propagação de doenças transmitidas pela água, além de poder afetar a biodiversidade local. Nesse contexto, a avaliação desse parâmetro serve como um indicador da poluição bacteriológica, indicando contaminação recente de matéria orgânica. Em todas as amostras analisadas, o parâmetro amônia demonstrou resultados dentro do VMP de $1,5 \mathrm{mg} \mathrm{L}^{-1} \mathrm{NH}_{3}$.

Quanto ao parâmetro dureza total, todas as amostras apresentaram valor dentro do estabelecido pelo Ministério da saúde. Segundo Ferreira et al. (2021), esse parâmetro não apresenta inconveniente sanitário, mas sim econômico, pois aumenta a resistência da água a saponificação diminuindo, assim, a formação de espuma, o que resulta em maior consumo de sabões e xampus. Além disso, causa sabor desagradável na água e pode contribuir para incrustações nas tubulações que abastecem as residências.

RC: 106324

Disponível em: https://www.nucleodoconhecimento.com.br/engenharia-agricola/qualidade-daagua 
De acordo com Matias et al. (2019), os cloretos estão presentes em quase todas as águas naturais e possuem origem na dissolução de sais como cloreto de sódio. A presença de cloretos acelera os processos de corrosão de tubulações de aço e alumínio, além de alterar o sabor da água. Concentrações elevadas de cloretos indicam poluição da água por esgoto doméstico. Todas as amostras analisadas estavam com os resultados para esse parâmetro dentro do que prevê a legislação (25 $\mathrm{mgL}^{-1} \mathrm{Cl}_{2}$ ).

De acordo com Brito (2013), a avaliação do ferro nas águas subterrâneas para o consumo humano se dá em função de suas propriedades organolépticas. O seu acúmulo em órgãos como o fígado, pâncreas e coração pode resultar em cirrose e tumores hepáticos além de diabetes mellitus e insuficiência cardíaca. Além disso, quantidades altas de ferro podem gerar radicais livres em excesso que atacam as moléculas celulares e, assim, aumentam o número de moléculas potencialmente cancerígenas dentro das células. Em todas as amostras analisadas, os valores de ferro obtidos foram de $0,2 \mathrm{mg} \mathrm{L}^{-1}$ estando dentro do VMP de $0,3 \mathrm{mg} \mathrm{L}^{-1}$ de Fe.

Segundo Oliveira (2011), o cloro é o desinfetante mais utilizado na produção de água potável, sendo empregado como desinfetante primário na grande maioria de estações de tratamento de água superficial e subterrânea, é utilizado tanto como prédesinfetante quanto pós-desinfetante e tem a principal função de inativar os organismos patogênicos e, consequentemente, auxiliar na prevenção de doenças

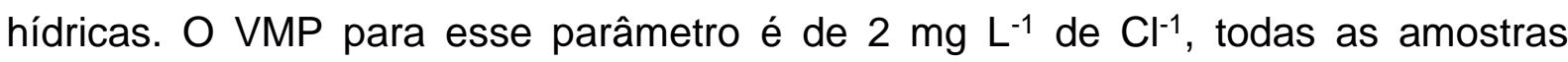
analisadas nesse trabalho estão com o valor de cloro dentro do que prevê a portaria do Ministério da Saúde.

A cor aparente é um indicativo da presença de substâncias, geralmente orgânicas, dissolvidas no corpo hídrico. É um parâmetro físico que trata da aparência e estética que a água deve ter (BRITO, 2013). Em relação ao parâmetro cor, na amostra de poço 1 (PA-1), apresentou-se valor de $25 \mathrm{mg} \mathrm{L}^{-1} \mathrm{Pt} / \mathrm{Co}$, resultado acima do limite

RC: 106324

Disponível em: https://www.nucleodoconhecimento.com.br/engenharia-agricola/qualidade-daagua 
estabelecido pela legislação (15 $\left.\mathrm{mg} \mathrm{L}^{-1} \mathrm{Pt} / \mathrm{Co}\right)$ e, o poço 2 (PA-2), apresentou resultado no limite.

A turbidez foi outro parâmetro que ficou fora dos padrões estabelecidos pela legislação (5 UNT) para a maioria das amostras (9 ao todo). A variação do parâmetro foi de 2 a 30 UNT. Todas as amostras obtidas nos poços artesianos (PA) e caminhão pipa $(\mathrm{CH})$ apresentaram valores acima do máximo permitido. Ainda, 2 (duas) amostras de chuva sem solução de hipoclorito de sódio 2,5\% (CSH-2e CSH-3) e 1(uma) amostra de chuva tratada com a solução $(\mathrm{CH}-3)$ apresentaram valores acima do Valor Máximo Permitido (VMP).

De acordo com Zerwes et al. (2015), a determinação da turbidez da água está fortemente ligada a presença de material sólido em suspensão, o que afeta a transparência da água. Quanto maior a quantidade de sólidos dispersos no corpo hídrico, maiores serão os valores dos parâmetros turbidez e cor. A turbidez não apresenta risco sanitário e está mais ligada a estética da água, o que compromete a aceitação ou não da mesma por parte do consumidor (BRITO, 2013). De acordo com Oliveira (2018), os parâmetros cor e turbidez podem ser corrigidos através do tratamento da água com filtro de areia e através da limpeza e manutenção das fontes de fornecimento de água.

Em relação a análise microbiológica, como podemos observar na (Tabela 2), apenas a amostra advinda de caminhão pipa (CP) não apresentou a presença de coliformes estando, portanto, dentro do que prevê a legislação, que é a ausência de coliformes na água destinada ao consumo humano.

RC: 106324

Disponível em: https://www.nucleodoconhecimento.com.br/engenharia-agricola/qualidade-daagua 
Tabela 2. Resultados da análise microbiológica da água para o consumo humano do Assentamento Jerusalém em Rubim-MG.

\begin{tabular}{|lr|ll|l|l|l|l|}
\hline PARÂMETRO & & *VMP & PA-1 & CP- & CH-1 & CSH-1 \\
\hline $\begin{array}{l}\text { Coliformes } \\
\text { (UFC/100mL) }\end{array}$ & totais & $\begin{array}{l}\text { Ausência em } \\
100 \mathrm{~mL}\end{array}$ & $78.933,33$ & - & $100.266,66$ & $74.666,66$ \\
\hline $\begin{array}{l}\text { Escherichia } \\
\text { (UFC/100mL) }\end{array}$ & coli & $\begin{array}{l}\text { Ausência em } \\
100 \mathrm{~mL}\end{array}$ & $40.533,33$ & - & - & - \\
\hline
\end{tabular}

Fonte: Autores (2019)

A ausência de coliformes na água advinda do caminhão pipa (CP) pode ser explicado pelo fato da distribuição dessa água ser feita pela Companhia de Saneamento de Minas Gerais (COPASA), que passa por um tratamento antes de ser distribuída.

De acordo com Melo e Andrade (2020), os microrganismos do grupo de coliformes não residem de forma natural na água, sendo introduzidos na mesma através de dejetos humanos, como material fecal, afetando o ser humano por meio de ingestão ou contato com água contaminada. Os coliformes termotolerantes pertencem a um grupo de microrganismos que tem habitat no trato intestinal do homem e de outros animais, portanto, sua presença em água e alimentos indica que houve contato direto do produto com fezes, evidenciando risco para a saúde dos consumidores devido sua alta patogenicidade (OLIVEIRA, 2011).

A presença de Coliformes totais nas amostras das águas analisadas não é, necessariamente, um indicativo de presença de Coliformes termotolerantes, conforme é apresentado na (Tabela 2), onde nas amostras de $\mathrm{CH}$ (água armazenada em cisterna com adição de hipoclorito) e CSH (água armazenada em cisterna sem adição de hipoclorito) as análises apontaram apenas a presença de coliformes totais,

RC: 106324

Disponível em: https://www.nucleodoconhecimento.com.br/engenharia-agricola/qualidade-daagua 
podendo ser utilizada como um indicador ambiental, representando apenas bactérias de vida livre e não intestinal.

No estudo conduzido por Silva et al. (2020), que analisou a qualidade da água em cisternas, os resultados para o parâmetro microbiológico foram acima do VMP em todas as cisternas analisadas. O autor, ainda, cita Andrade Neto (2003), que afirma que vários estudos sobre a qualidade de águas de chuva armazenadas em cisternas têm demonstrado que estas, geralmente, atendem aos padrões de potabilidade para os parâmetros físico-químicos. No entanto, frequentemente não atendem aos padrões de potabilidade quanto aos critérios de qualidade microbiológica.

As amostras de água advindas de poços artesianos utilizados para obtenção de água no Assentamento Jerusalém apresentaram VMP acima do que prevê a legislação, tanto para coliformes totais, quanto para coliformes termotolerantes (E. coli). Trabalhos realizados por Oliveira (2018) e Oliveira (2011), que também realizaram análises da qualidade da água de poços em comunidades rurais, obtiveram resultados com valores maiores do que o VMP, estando, no primeiro estudo, $70 \%$ das amostras contaminadas e, no segundo, $88,14 \%$ estavam contaminadas com coliformes totais e $65,38 \%$ com E. coli.

De acordo com Oliveira (2018), a presença de coliformes nas águas analisadas em seu estudo pode ser explicada pelas más condições de construção dos poços e pelas proximidades de fossas sépticas decorrente de poluição de fezes humanas. Isso pode explicar a presença de coliformes na água de poço artesiano analisado no Assentamento Jerusalém, pois durante a visita foi possível verificar a presença de fezes de animais próximos aos reservatórios.

\section{CONSIDERAÇÕES FINAIS}

O objetivo do trabalho foi avaliar a potabilidade da água utilizada pelos moradores do Assentamento Jerusalém, localizado no município de Rubim - MG, utilizando um Kit

RC: 106324

Disponível em: https://www.nucleodoconhecimento.com.br/engenharia-agricola/qualidade-daagua 
Técnico de Potabilidade (Alfakit), tendo em vista que nas áreas rurais o acesso à água potável é negligenciado, quando comparado com as áreas urbanas.

O Kit Técnico de Potabilidade utilizado demonstrou-se prático e de fácil manuseio. Diante dos resultados obtidos, observa-se que, dentre os parâmetros físico-químicos analisados, a turbidez e a cor apresentaram valores fora dos padrões estabelecidos pela legislação para algumas amostras. Esses dois parâmetros estão interligados e apresentam mais conotação estética do que sanitária, podendo ser corrigidos com a limpeza dos reservatórios e filtração da água para o consumo.

Uma atenção deve ser dada em relação à água proveniente do poço artesiano (PA$1)$, por ter apresentado coliformes termotolerantes ( $E$. colli), o que indica a presença direta de fezes na água consumida, o que a torna inapropriada para o consumo humano.

Os resultados apontam que as análises microbiológicas devem ser realizadas em outras fontes de água no Assentamento Jerusalém, a fim de se verificar como está e relatar para a população e órgãos competentes sobre os possíveis riscos em relação às doenças que podem ser transmitidas pela água. Um outro estudo sobre o levantamento de doenças de veiculação hídrica que acomete essa população rural pode ser realizado em parceria com a Secretaria Municipal de Saúde, para verificar a incidência e fornecer dados para a tomada de decisão por parte dos órgãos competentes.

\section{REFERÊNCIAS}

ALFAKIT, 2019. Polikit Potabilidade - Kit desenvolvido para controle de qualidade da água para consumo humano. Disponível em: https://alfakit.com.br/produtos/polikitpotabilidade-cod-4117/. Acesso em: 10/10/2019.

RC: 106324

Disponível em: https://www.nucleodoconhecimento.com.br/engenharia-agricola/qualidade-daagua 
BIRKHEUER, C. D. F et al. Qualidade físico-química e microbiológica da água de consumo humano e animal do Brasil: análise sistemática. Revista Caderno Pedagógico, v. 14, n. 1, 2017.

BRASIL, 2017. Portaria de Consolidação o 05 de 28 de setembro de 2017, Anexo XX -Do controle e da vigilância da qualidade da água para consumo humano e seu padrão de potabilidade, p. 205-218.

BRITO, Priscila Nazaré de Freitas. Qualidade da água de abastecimento em comunidades rurais de várzea do Baixo Rio Amazonas. 2013. 50p. Monografia (Bacharel em Ciências Ambientais) - Universidade Federal do Amapá, Macapá, 2013.

CABRAL D. N, ARAÚJO D. S. Qualidade da água em áreas rurais: análise bacteriológica e físico-química das águas dos tanques de pedra das comunidades KM 21 (Campina Grande) e Pedra Redonda (Pocinhos). Revista Brasileira de Geografia Física, v. 9, n. 06, p. 1737-1753, 2016.

FERREIRA, L. A.; PIMENTEL, E. T.; SILVA, R. B. P.; SANTOS, A. A. Avaliação da qualidade de potabilidade da água subterrânea em áreas rurais no município de Humaitá/AM. Revista Ibero-Americana de Ciências Ambientais, v.12, n.1, p.721729, 2021.

MATIAS, A. O et al. ANÁLISE DA QUALIDADE DA ÁGUA DE TRÊS PROPRIEDADES RURAIS DO MUNICÍPIO DE FLORIANO-PIAUÍ. Revista Brasileira de Agropecuária Sustentável, v. 9, n. 2, 2019.

MELO, C. M. T; ANDRADE, W. C. Aspectos físico-químicos e microbiológicos da água de consumo disponível para a comunidade rural de Patrimônio dos Poncianos/M. DESAFIOS-Revista Interdisciplinar da Universidade Federal do Tocantins, v. 7, n. 3, p. 337-348, 2020.

RC: 106324

Disponível em: https://www.nucleodoconhecimento.com.br/engenharia-agricola/qualidade-daagua 
OLIVEIRA, Kildrey Aquino de. Qualidade da água para consumo humano em solução alternativa de abastecimento no município do Cabo de Santo Agostinho, Pernambuco. 2011. 16p. Monografia (Especialização em saúde pública) - Departamento de Saúde Coletiva, Centro de Pesquisas Aggeu Magalhães, Fundação Oswaldo Cruz, Recife, 2011.

OLIVEIRA, Michael Machado et al. Análise físico-química e microbiológica de águas de poços artesianos de uso independente. Revista Gestão \& Sustentabilidade Ambiental, v. 7, n. 3, p. 624-639, 2018.

PATIAS, I. D. S et al. Análise físico-química e microbiológica de águas subterrâneas utilizadas no abastecimento de zonas rurais de Jaguari, Rio Grande do Sul, Brasil. PERSPECTIVA, Erechim v. 40, n. 151, p. 73-82, setembro - 2016

SILVA, J. P.; BEZERRA, C. E.; RIBEIRO, A. de A. Avaliação da qualidade da água armazenada em cisternas no Semiárido Cearense. Revista Brasileira de Engenharia de Biossistemas, v. 14, n. 1, p. 27-35, 2020.

ZERWES, Cristian Mateus et al. Análise da qualidade da água de poços artesianos do município de Imigrante, Vale do Taquari/RS. Ciência e Natura, v. 37, n. 3, p. 651663, 2015.

Enviado: Dezembro, 2021

Aprovado: Fevereiro, 2022.

RC: 106324

Disponível em: https://www.nucleodoconhecimento.com.br/engenharia-agricola/qualidade-daagua 